\title{
Article \\ Microbial Synthesis and Evaluation of Fungistatic Activity of 3-Butyl-3-hydroxyphthalide, the Mammalian Metabolite of 3-n-Butylidenephthalide
}

\author{
Joanna Gach *(D), Teresa Olejniczak*(D), Piotr Krężel and Filip Boratyński
}

check for

updates

Citation: Gach, J.; Olejniczak, T.; Krężel, P.; Boratyński, F. Microbial Synthesis and Evaluation of Fungistatic Activity of 3-Butyl-3-hydroxyphthalide, the Mammalian Metabolite of

3-n-Butylidenephthalide. Int. J. Mol. Sci. 2021, 22, 7600. https://doi.org/ 10.3390/ijms22147600

Academic Editor: Barbora Szotáková

Received: 21 May 2021

Accepted: 13 July 2021

Published: 15 July 2021

Publisher's Note: MDPI stays neutral with regard to jurisdictional claims in published maps and institutional affiliations.

Copyright: (c) 2021 by the authors. Licensee MDPI, Basel, Switzerland. This article is an open access article distributed under the terms and conditions of the Creative Commons Attribution (CC BY) license (https:// creativecommons.org/licenses/by/ $4.0 /)$.
Department of Chemistry, Wrocław University of Environmental and Life Sciences, Norwida 25, 50-375 Wrocław, Poland; piotr.krezel@outlook.com (P.K.); filip.boratynski@upwr.edu.pl (F.B.)

* Correspondence: joanna.gach@upwr.edu.pl (J.G.); teresa.olejniczak@upwr.edu.pl (T.O.)

\begin{abstract}
Phthalides are bioactive compounds that naturally occur in the family Apiaceae. Considering their potentially versatile applications, it is desirable to determine their physical properties, activity and metabolic pathways. This study aimed to examine the utility of whole-cell biocatalysts for obtaining 3-butyl-3-hydroxyphthalide, which is the metabolite formulated during mammalian metabolism of 3- $n$-butylidenephthalide. We performed transformations using 10 strains of fungi, five of which efficiently produced 3-butyl-3-hydroxyphthalide. The product yield, determined by high-performance liquid chromatography, reached 97.6\% when Aspergillus candidus AM 386 was used as the biocatalyst. Increasing the scale of the process resulted in isolation yields of $29-45 \%$ after purification via reversed-phase thin layer chromatography, depending on the strain of the microorganism used. We proposed different mechanisms for product formation; however, hydration of 3- $n$-butylidenephthalide seems to be the most probable. Additionally, all phthalides were tested against clinical strains of Candida albicans using the microdilution method. Two phthalides showed a minimum inhibitory concentration, required to inhibit the growth of $50 \%$ of organisms, below $50 \mu \mathrm{g} / \mathrm{mL}$. The 3- $n$-butylidenephthalide metabolite was generally inactive, and this feature in combination with its low lipophilicity suggests its involvement in the detoxification pathway. The $\log P$ value of tested compounds was in the range of 2.09-3.38.
\end{abstract}

Keywords: biotransformations; Apiaceae; bioactivity; phthalides; lipophilicity; lactones; antifungal activity

\section{Introduction}

Phthalides are a group of bioactive secondary metabolites that are found mainly in plants from the family Apiaceae, such as Angelica acutiloba, Angelica sinensis, Apium graveolens, Cnidium officinale, Levisticum officinale and Ligusticum porteri [1-6]. These compounds have been widely tested for their pharmacological properties [7-11]. 3- $n$-butylphthalide has been authorized for treating brain ischemia in China [7]. Moreover, the analog of this compound, 3-n-butylidenephthalide, showed a positive effect on the cardiovascular system, inhibiting angiogenesis in vitro, ex vivo and in vivo in animal models [8]. Furthermore, 3- $n$-butylidenephthalide also exhibited neuroprotective activity by reducing secreted proinflammatory molecules in rat brain glial cells, thus increasing the lifespan of mice with amyotrophic lateral sclerosis $[9,10]$. A study also reported its antihyperglycemic activity in an animal model [11].

Phthalides have also been examined as potential fungistatic agents. 3 - $n$-butylidenephthalide appeared to be more active against dermatophytes than the antifungals itraconazole and ketoconazole [12]. Significantly, similarly structured 3- $n$-butylphthalide inhibited the growth of four clinical strains of Candida albicans, while the reference drug, fluconazole, was inactive at much higher concentrations [13]. Candida species are one of the most common causes of fungal infections worldwide. Even though these microorganisms are ubiquitous 
in humans, they can establish mucus membrane infections in cases of microbiome disturbances or even severe systemic candidiasis in immunocompromised patients [14-16]. The development of novel antifungals is necessitated by the rising resistance of Candida yeasts to antifungals, such as azoles, and drawbacks of these compounds, such as toxicity and possible drug-drug interactions [17-20]. Notably, approximately $80 \%$ of antifungal agents are not investigated owing to their adverse effects [20]. The possible pharmacological application of phthalides warrants the assessment of their metabolic pathways. It is crucial to evaluate the toxicity and bioavailability of novel treatments at the earliest possible stage in order to avoid problems during subsequent phases. For instance, compounds may undergo bioactivation to reactive hepatotoxic derivatives [21]. Thus, the products of phthalide metabolism must be studied extensively. The small amounts of drug metabolites tested in vivo may pose an issue with their detection [22]; therefore, the in vitro preparation of metabolites may allow for easier determination of their structure and facilitate further investigations. Microbial whole-cell transformation is a viable system utilized for this purpose; it enables the metabolite to be obtained in high quantities and at a feasible cost [23].

Fungi-mediated biotransformations allow production of compounds with high regioand stereoselectivity through reduction, oxidation, epoxidation, hydrogenation, hydrolysis, amination, acylation, glucosylation, epoxidation, hydration, methylation and hydroxylation by cytochrome P450 enzymes, especially regarding steroid conversion [24-26]. Moreover, the valuable characteristic of a fungi-based approach is the complexity of their metabolic abilities, allowing for xenobiotic degradation that is partially reminiscent of mammalian metabolism [26].

Diao et al. reported that hydroxylation of 3- $n$-butylphthalide, a saturated analogue of 3-n-butylidenephthalide, was the main metabolic route in humans, and that this hydroxylation occurred on the side chain instead of the relatively stable benzene ring. Similarly, use of this substrate in the culture of Cunninghamella blakesleana ATCC9244 also yielded hydroxylated compounds, including hydroxy-3-butylphthalide [27]. Furthermore, Yan et al. reported the formation of this product during the metabolism of 3-n-butylidenephthalide in rats [28]. Nevertheless, 3- $n$-butylidenephthalide has not previously been transformed using microbial whole cells.

Lipophilicity, defined as the affinity of a compound towards nonpolar phase, is also significant for potential drug evaluation [29]. The $\log P$ parameter is linked to the absorption, distribution, metabolism and excretion processes [30,31]. It has been shown that lipophilicity that is too high is associated with undesirable properties, such as accumulation of the compound in the adipose tissue [32]. According to Lipinski's rule of five, the $\log P$ value should not exceed 5 [33].

Research on phthalides and their metabolites should focus not only on determining their structure, but also on assessing their physical properties, activity and metabolic pathways by analyzing structural analogs. Therefore, our primary aim was to determine whether the fungi transform 3-n-butylidenephthalide to 3-butyl-3-hydroxyphthalide: the identical compound that is formed in small quantities during rat metabolism, precluding its isolation. Efficient synthesis of this metabolite using microorganisms would be an attractive alternative approach in comparison to chemical synthesis.

Moreover, we aimed to elucidate the mechanisms of the biotransformation process. Considering the possible pharmacological applications of this research, we also assessed the lipophilicity of the substrate and its metabolite and compared their inhibitory potential against four Candida albicans strains.

\section{Results and Discussion}

Screening biotransformations involving fungal strains were performed to select the most effective biocatalysts for producing 3-butyl-3-hydroxyphthalide (2). This approach allowed the resulting microorganisms to be used in scale-up processes to isolate the metabolite and confirm its structure by nuclear magnetic resonance (NMR) spectroscopy 
(Figures S1-S16, Supplementary Materials). Next, we evaluated the lipophilicity of compounds using reversed-phase high-performance liquid chromatography (RP-HPLC) and tested their antimicrobial properties against selected Candida yeasts. We also aimed to establish whether a metabolite with a different polarity also exhibits bioactive potential or is suggestive of xenobiotic detoxification.

\subsection{Biotransformations of 3- $n$-Butylidenephthalide (1)}

To obtain 3-butyl-3-hydroxyphthalide (2) from 3- $n$-butylidenephthalide (1), wholecells of fungi were used (Figure 1).

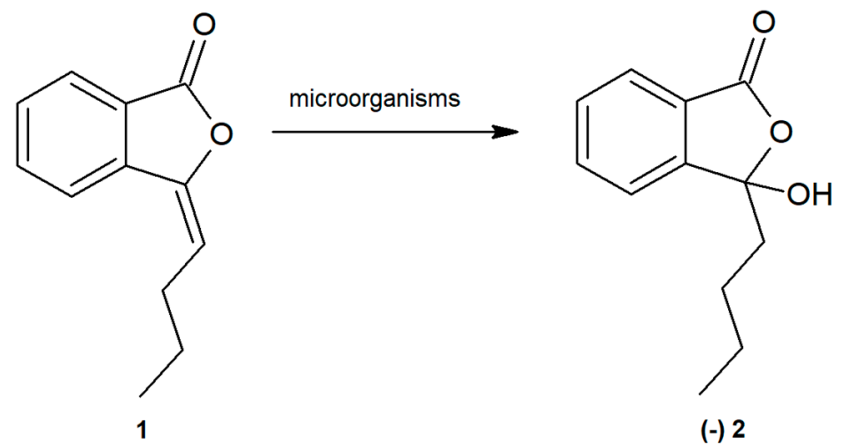

Figure 1. Biotransformation of 3-n-butylidenephthalide (1) to (-)-3-butyl-3-hydroxyphthalide (2) using whole fungal cells.

Initially, screening-scale biotransformation of 3-n-butylidenephthalide (1) was conducted using 10 fungal strains, which were analyzed for their catalytic potential. These strains included Absidia cylindrospora AM 336, Ascosphaera apis AM 496, Aspergillus candidus AM 386, Chaetomium indicum AM 158, Fusarium culmorum AM 9, Fusicoccum amygdali AM 258, Laetisporus sulphurens AM 515, Mucor spinosus AM 398, Penicillium chrysogeum AM 112 and Pycnidiella resinae AM 50 (data not shown). Of these, the five strains that exhibited the most efficient product (2) formation were Aspergillus candidus AM 386, Absidia cylindrospora AM 336, Mucor spinosus AM 398, Chaetomium indicum AM 158 and Pycnidiella resinae AM 50. These five strains were chosen for further screening.

Biotransformation of 3- $n$-butylidenephthalide $(\mathbf{1})$ as a mixture of $(E)$ and $(Z)$ isomers (9:1) at a concentration of $0.27 \mathrm{mg} / \mathrm{mL}$ was carried out for 14 days at $25^{\circ} \mathrm{C}$ with shaking culture in Sabouraud medium. Samples were taken every 2 days, extracted with ethyl acetate and analyzed via thin layer chromatography (TLC) and HPLC (Figures S14-16, Supplementary Materials).

The highest product (2) yield of $97.61 \%$ was obtained using A. candidus AM 386 on day 4 , as determined by HPLC (Figure 2). However, in contrast to that in other strains, A. candidus AM 386 further metabolized compound (2) to unidentified derivatives. The other tested microorganisms, A. cylindrospora AM 336, M. spinosus AM 398, C. indicum AM 158 and P. resinae AM 50, produced yields between $25.13 \%$ and $72.40 \%$ by day 14 . We also focused on the $\mathrm{pH}$ of the cultures over the course of the biotransformations (Figure 3). In cultures with M. spinosus AM 398 and P. resinae AM 50, the conditions were slightly acidic ( $\mathrm{pH}$ 5-6), whereas the A. cylindrospora AM 336 and C. indicum AM 158 strains subtly alkalized the culture ( $\mathrm{pH} 7.4-8.5$ ). In the $A$. candidus AM 386 culture, the $\mathrm{pH}$ was in the range of 5.5-5.0 in the first few days but subsequently increased to 8.5 . The sudden change in $\mathrm{pH}$ value presumably occurred due to the change in nutrient availability. During culture growth, depletion of the carbon source causes stress for the microbial cells, resulting in extracellular release of ammonia [34]. The stability of the compounds under extreme $\mathrm{pH}$ conditions were examined using a mixture of substrates and products. 


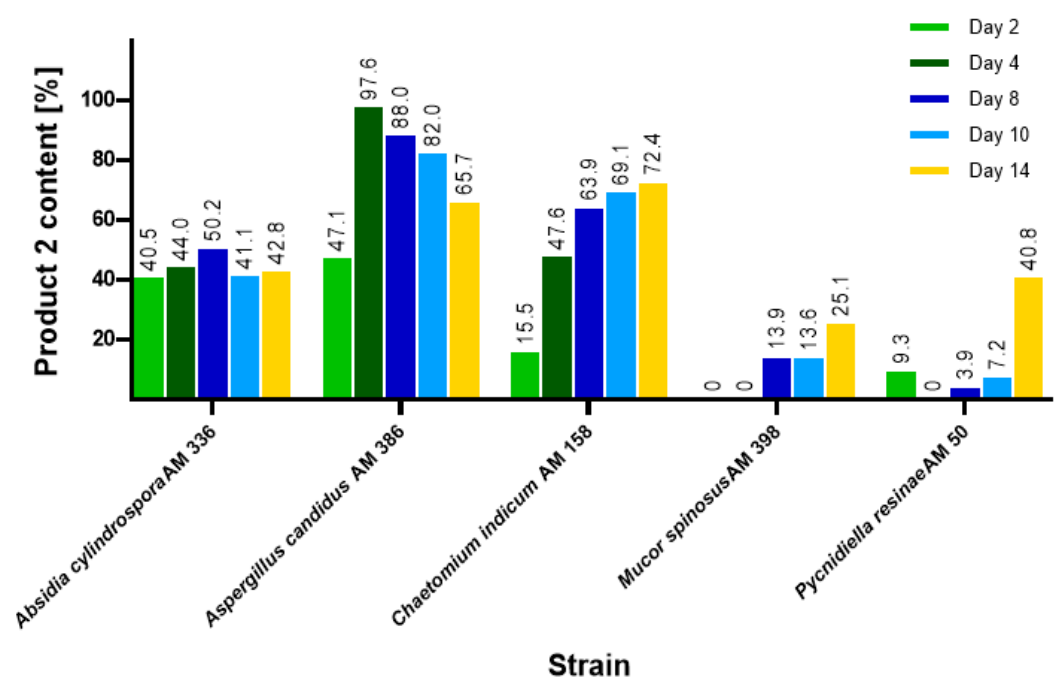

Figure 2. Content of product (2) during the screening-scale biotransformations of 3- $n$ butylidenephthalide (1) determined using a high-performance liquid chromatography-diode array detector.

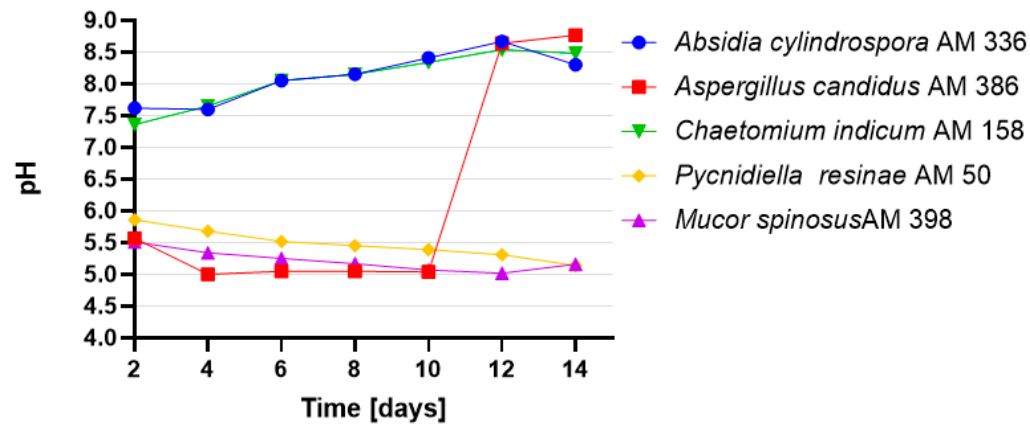

Figure 3. $\mathrm{pH}$ values of cultures during the screening-scale transformations of 3- $n$-butylidenephthalide (1).

In order to confirm the structure of compound (2) and determine its mechanism of action, we scaled up the biotransformation with the following strains: A. candidus AM 386, A. cylindospora AM 336 and C. indicum AM 158. We decided to use three strains on a preparative scale instead of focusing on only one of them, as the isolation yields of product (2) might have been diversified. This issue may result from different metabolite concentrations in particular strains, which are not visible during screening-scale transformation while the biotransformation is monitored by HPLC. We also sought to determine the stereoselectivity of the process for particular strains. Biotransformations were performed in 2000-mL shaken flasks with 3-n-butylidenephthalide (1) at a concentration of $150 \mathrm{mg} / 500 \mathrm{~mL}$ at $25^{\circ} \mathrm{C}$. The products were analyzed using gas chromatography (GC), HPLC and RP-TLC. All three microorganisms sufficiently transformed 3-n-butylidenephthalide (1) (Figure 4). The conversion of the substrate was slower in C. indicum AM 158, which is consistent with the results of the small-scale experiments. The biotransformations continued until day 14 with the exception of $A$. candidus AM 386, which was only continued to day 8 because of an observed decrease in product yield. 


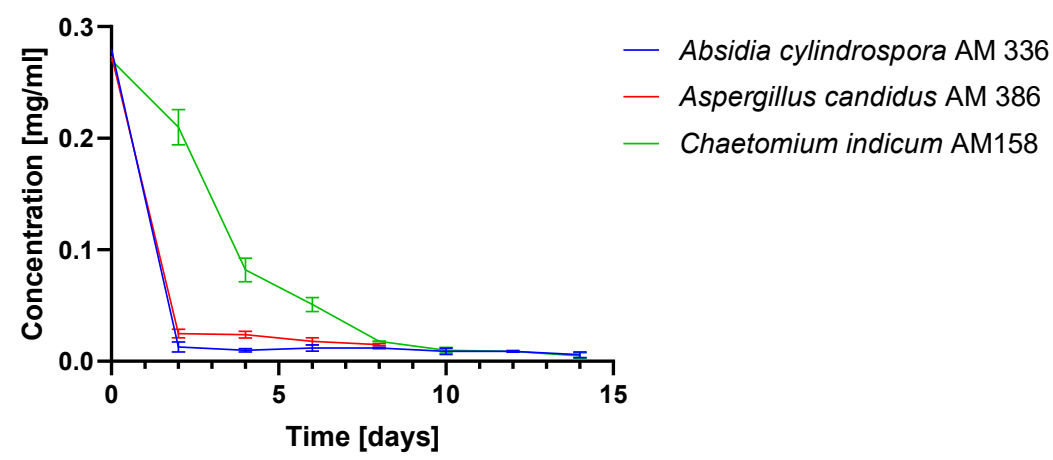

Figure 4. Change in 3- $n$-butylidenephthalide (1) concentration during scale-up biotransformation determined by gas chromatography.

The $\mathrm{pH}$ of the culture media was in the range of 7-8.25 when using fungi from the genera Chaetomium and Absidia. Meanwhile, the $\mathrm{pH}$ of cultures of fungi from the genus Aspergillus was acidic and remained stable at $\mathrm{pH} 5$ during biotransformation. Monitoring the $\mathrm{pH}$ value allowed us to determine whether it was necessary to acidify the samples to extract the product from the organic phase. The biotransformation mixtures were extracted by ethyl acetate and purified on RP-TLC plates (Figure S12, Supplementary Materials).

Using NMR spectra, we confirmed that the main isolated product of the biotransformation was (-)-3-butyl-3-hydroxyphthalide (2). The assignment of aromatic signals of 3-butyl-3-hydroxyphthalide (2) in the range of $\delta=7.56-7.81 \mathrm{ppm}$ was mainly allowed by Correlation Spectroscopy (COSY) (coupling of H-5 with H-6 and H-4 protons). This was also facilitated via Nuclear Multiple Bond Coherence (HMBC) spectrum coupling of C-13 with protons $\mathrm{H}-5$ and $\mathrm{H}-7$ without correlation with $\mathrm{H}-4$, as well as a coupling of C-12 with H-4 and H-6 without correlation with H-7 (Figure 5). The presence of a hydroxyl group was confirmed by the broad signal in the range of $\delta=3.70-4.50 \mathrm{ppm}$ (Figure S3, Supplementary Materials). The characteristic signal for the proton $\mathrm{H}-8$ in the substrate structure at $\delta=5.64$ was absent in the spectra of this derivative. The signal for the carbon atom with the hydroxyl group (C-3) in the 3-butyl-3-hydroxyphthalide (2) spectrum was shifted upfield $(\delta=107.9)$ when compared to that of the unsubstituted carbon atom $(\delta=145.9)$ in the precursor compound (1) (Figure S4, Supplementary Materials).
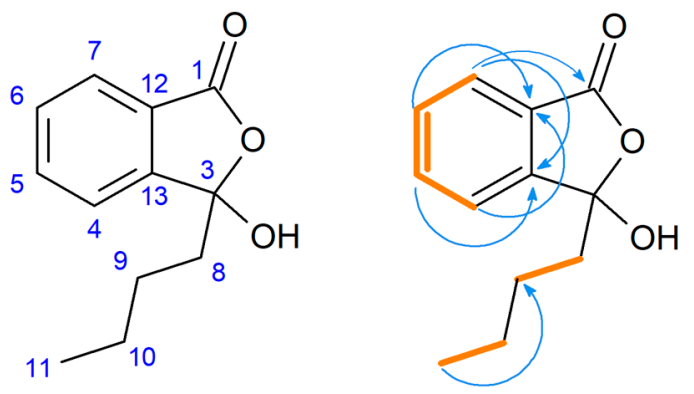

Figure 5. Pivotal Correlation Spectroscopy (orange bolded) and Nuclear Multiple Bond Coherence (arrows) correlations of 3-butyl-3-hydroxyphthalide (2).

Overall, the yield of the product (2) in the biotransformation mixture at the end of the process was in the range $57-82 \%$ depending on the strain used, as determined by HPLC. The yield after isolation was approximately $29-45 \%$ (Table 1 ). The specific rotations $[\alpha] \begin{gathered}25 \\ 589\end{gathered}$ of product (2) isolated from particular strains were as follows: -2.4 (c = 1.0, $\left.\mathrm{CHCl}_{3}\right)$ for A. cylindrospora AM 336; $-0.5\left(\mathrm{c}=1.0, \mathrm{CHCl}_{3}\right)$ for A. candidus AM 386; and -3.6 (c = 1.0, $\mathrm{CHCl}_{3}$ ) for C. indicum AM 158. 
Table 1. Product (2) content in the biotransformation mixtures at the end of the processes both before and after isolation.

\begin{tabular}{cccc}
\hline Strain & $\begin{array}{c}\text { Time of the Process } \\
\text { [Days] }\end{array}$ & \multicolumn{2}{c}{ 3-Butyl-3-hydroxyphthalide (2) } \\
\cline { 3 - 4 } & 14 & 69.8 & 36.6 \\
\hline $\begin{array}{c}\text { Chaetomium indicum } \\
\text { AM 158 }\end{array}$ & 14 & 57.0 & 29.2 \\
\hline $\begin{array}{c}\text { Absidia cylindospora } \\
\text { AM 336 }\end{array}$ & 8 & 82.2 & 45.4 \\
\hline $\begin{array}{c}\text { Aspergillus candidus } \\
\text { AM 386 }\end{array}$ & & & (Isolation Yield) [\%] \\
\hline
\end{tabular}

\subsection{Proposed Pathways for 3-Butyl-3-hydroxyphthalide (2) Formation}

Hydroxylation frequently occurs via cytochrome P450 enzymes involved in xenobiotic metabolism [35]. To examine the possibility of 3-butyl-3-hydroxyphthalide (2) formation through hydroxylation of the saturated analog (4) of 3- $n$-butylidenephthalide (1) (Figure 6), we also performed biotransformations of 3-n-butylphthalide (4) using the three previously used microorganisms.

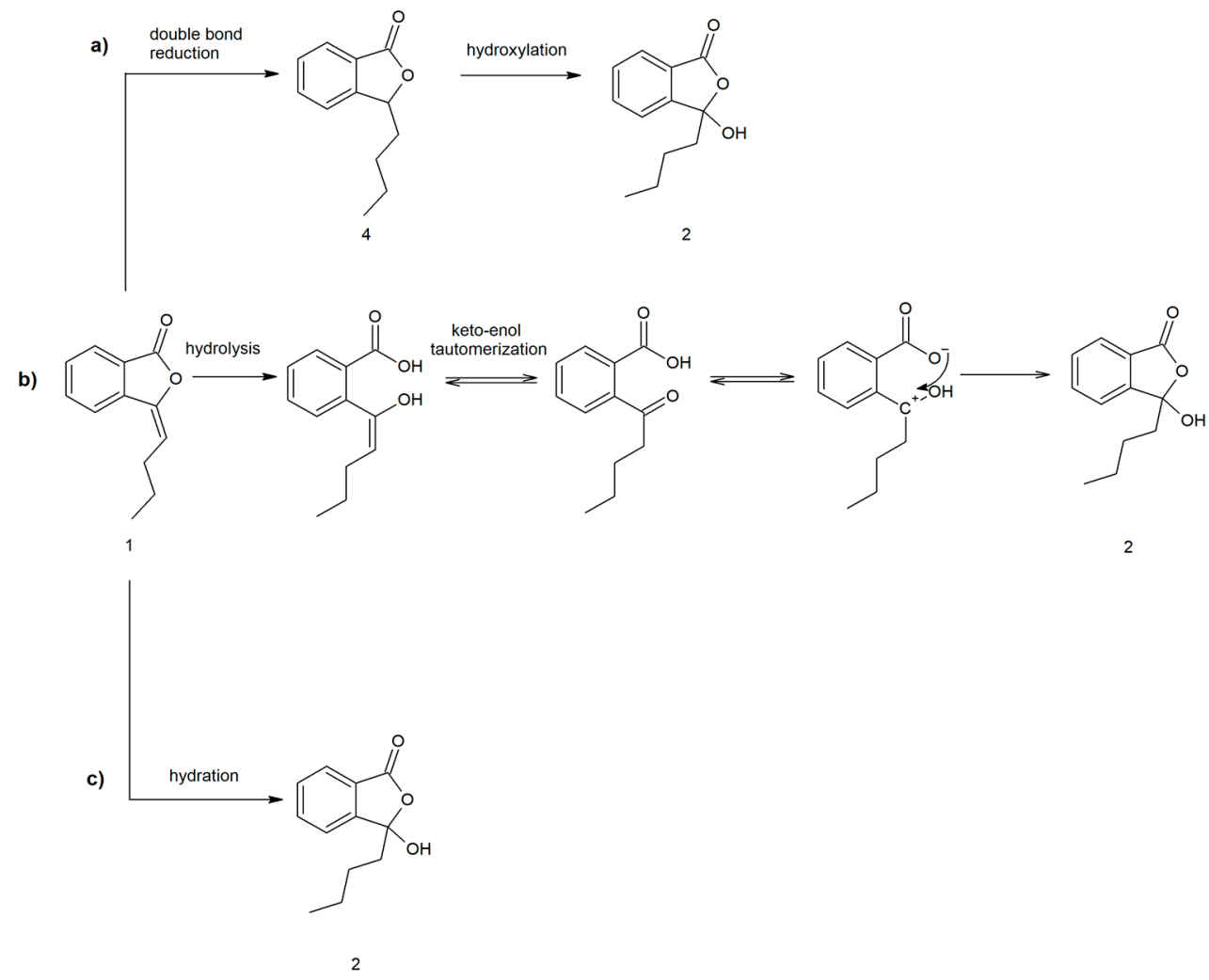

Figure 6. Proposed mechanism of 3-butyl-3-hydroxyphthalide (2) formation via (a) the intermediary product 3-n-butylphthalide (4); (b) hydrolysis of 3-n-butylidenephthalide (1) and (c) hydration of 3-n-butylidenephthalide (1).

However, our experiments showed that 3-n-butylphthalide (4) was not converted to product (2). We used ${ }^{13} \mathrm{C}$ NMR as a diagnostic tool to analyze the biotransformation mixture. Spectra of the biotransformation mixtures showed a lack of the characteristic signal for the C-3 carbon in 3-butyl-3-hydroxyphthalide (2) at $\delta=107.9 \mathrm{ppm}$ (Figure S13, Supplementary Materials). Additionally, the saturated analog (4) of 3-n-butylidenephthalide (1) was not observed during the biotransformations. Therefore, the possibility of the conversion of 
the compound (1) through the reduction of a double bond followed by hydroxylation was rejected.

Another proposed mechanism involves the microbial hydrolysis of 3- $n$-butylidenephthalide (1), keto-enol tautomerism and the closing of the lactone moiety (Figure 6). Aldol-lactonizations may be selectively conducted by enzymes [36]; however, in the proposed mechanism, the molecule with a positive charge on C-3 carbon is formed ( $\mathrm{sp}^{2}$ hybridization). Such flat carbocation is attacked by all sides of the plane, and thus, obtainment of a racemate is probable. Therefore, as we obtained an optically active product, we excluded this mechanism as a possibility.

The most probable pathway included hydration, which is the addition of water to a double bond in the C-3 position (Figure 6). The hydration route was also proposed by Yan et al. when they investigated the conversion pathway of ligustilide in rat plasma, as well as in later research concerning the metabolism of 3-n-butylidenephthalide (1). The researchers proposed the aromatization of ligustilide to $3-n$-butylidenephthalide (1), with a further addition of water to obtain 3-butyl-3-hydroxyphthalide (2) [28,37]. Hydratases reportedly have certain advantages over synthetic catalyst-mediated enantioselective hydration, as the latter often requires harsh environmental conditions [38].

Unfortunately, to the best of our knowledge, there is no available data on phthalide hydratases. In order to exclude acid-catalyzed hydration as a possible mechanism, compound (1) was additionally dissolved in a water and organic solvent mixture (35:65) in the presence of $\mathrm{HCl}(\mathrm{pH}=1)$. Compound (2) was not observed during HPLC analysis of the sample.

Interestingly, Li et al. observed the further methylation of product (2) in rat bile as a metabolite of a Chinese herbal formula containing phthalides, including 3- $n$-butylidenephthalide (1) [39]. Even though 3-butyl-3-methoxyphthalide (3) (Figure 7) was not observed during biotransformations in the cultures of fungal strains, we chemically synthesized this compound. We conducted hydrolysis and a reaction with boron trifluoride of the biotransformation mixture from A. candidus AM 386. We then examined whether the incorporation of a methoxy group affects the bioactivity. The substitution of the hydroxyl group in 3-butyl-3-methoxyphthalide (3) was evidenced by the presence of a three-proton singlet at 3.04 ppm (H-3a) (Figure S8, Supplementary Materials).<smiles>CCCCC1(OC)OC(=O)c2ccccc21</smiles>

Figure 7. Product (3-butyl-3-methoxyphthalide) (3) of the esterification of the biotransformation mixture of Aspergillus candidus AM 386.

\subsection{Influence of Lipophilicity and Fungistatic Activity}

Xenobiotics are usually converted to more polar metabolites so that they are easily excreted from the organism. The converted compounds may exhibit pharmacological activity or become inactive [21]. We planned to determine whether there is a dependent relationship between the polarity of the metabolite (2) of 3-n-butylidenepthalide (1) and its bioactivity. In order to achieve this, we evaluated the pharmacodynamic parameters and fungistatic properties of these compounds. 
To assess the lipophilicity of phthalides and their metabolites, the chromatographic partition coefficient $(\log \mathrm{kw})$ and hydrophobicity index $\left(\varphi_{0}\right)$ values were determined using RP-HPLC based on retention parameters. The partition coefficient $(\log P)$ values were calculated using theoretical methods proposed at ALOGPS 2.1.

RP-HPLC is a useful method for preliminary research into drug lipophilicity due to the small amount of compound required [40]. The method is based on the evaluation of the retention factor $(\mathrm{k})$. It has been previously stated that there is a linear correlation between the $\log \mathrm{k}$ value and the volume fraction of organic solvent [41]. This dependence, involving the $\log \mathrm{k}$ values of five compounds, is presented in Figure 8.

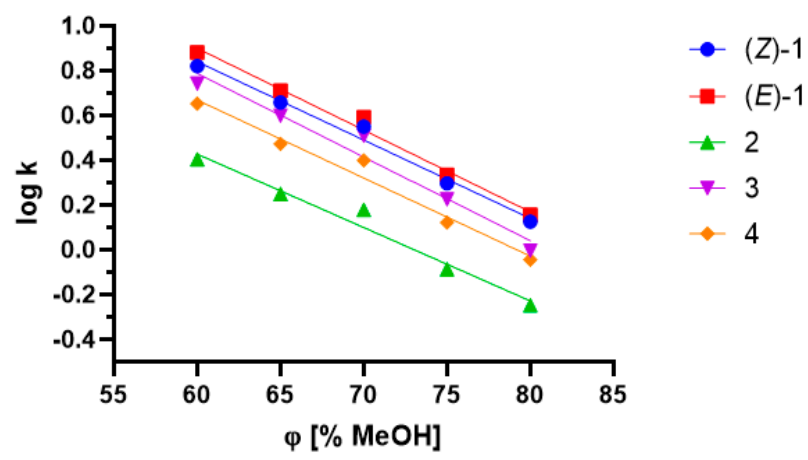

Figure 8. Log $\mathrm{k}$ and methanol volume fraction dependence for 3- $n$-butylidenephthalide (1); 3-butyl3-hydroxyphthalide (2); 3-butyl-3-methoxyphthalide (3); and 3-n-butylphthalide (4).

The chromatographic lipophilicity parameters are presented in Table 2. Overall, high coefficient values of determination $(\geq 0.9633)$ were obtained for all the examined compounds. The highest $\log \mathrm{k}_{\mathrm{w}}$ value was achieved for 3- $n$-butylidenephthalide (1) at -3.094 for isomer $(E)$. The metabolite of the abovementioned compound, 3-butyl-3hydroxyphthalide (2), had a notably higher polarity $\left(\log k_{w}=2.397\right)$. This result confirmed the introduction of a new polar group into the compound, which is typical for phase 1 reactions [21]. Introduction of a methyl group into the structure of 3-butyl-3-methoxyphthalide (3) resulted in increased hydrophobicity $\left(\varphi_{0}=81.200\right)$ in comparison to $(2)\left(\varphi_{0}=73.079\right)$. The lack of a double bond in the side chain of 3-n-butylphthalide (4) resulted in a higher polarity $\left(\log k_{\mathrm{w}}=2.7623\right)$ compared with that of compound $(\mathbf{1})$. The $\log P$ values according to ALOGPS 2.1 did not exceed 3.38 for the abovementioned compounds.

Table 2. Chromatographic partition coefficient (log kw) and hydrophobicity index $\left(\varphi_{0}\right)$ for substrate (1) and products of its conversion (3-butyl-3-hydroxyphthalide (2), 3-butyl-3-methoxyphthalide (3) and 3- $n$-butylphthalide (4)) along with the calculated partition coefficient.

\begin{tabular}{ccccccc}
\hline Compound & $\mathbf{L o g} \mathbf{k}_{\mathbf{w}} * \boldsymbol{}$ & $\begin{array}{c}\text { Standard } \\
\text { Error for } \\
\text { the Slope }\end{array}$ & $\begin{array}{c}\text { Standard } \\
\text { Error for the } \\
\text { Intercept }\end{array}$ & $\begin{array}{c}\text { Coefficient } \\
\text { of Deter- } \\
\text { mination }\end{array}$ & $\boldsymbol{\varphi}_{\mathbf{0}} * *$ & $\begin{array}{c}\text { Log } \boldsymbol{P}(\mathrm{Cal}- \\
\text { culated) }\end{array}$ \\
\hline$(Z)-1$ & 2.9422 & 0.0025 & 0.1747 & 0.9851 & 84.063 & 3.38 \\
$*(E)-1^{*}$ & 3.094 & 0.0024 & 0.1673 & 0.9875 & 84.536 & 3.38 \\
2 & 2.397 & 0.0032 & 0.2256 & 0.9721 & 73.079 & 2.09 \\
3 & 3.029 & 0.0042 & 0.2958 & 0.9633 & 81.200 & 2.86 \\
4 & 2.7623 & 0.0032 & 0.2256 & 0.9752 & 79.149 & 3.00 \\
\hline
\end{tabular}

* The separation of $(Z)$ and $(E)$ isomers are shown on the chromatogram (Figure S14, Supplementary Materials);

** The $\mathrm{r}$ value, indicating the correlation between measured $\log \mathrm{k}_{\mathrm{w}}$ and calculated $\log P$ values, is 0.8675 .

It has been previously stated that $90 \%$ of compounds that reach phase 2 clinical trials do not exceed a $\log P$ value of 5 [33]. Studies conducted by Tamaian et al. (2015) on thiazolylcarbonyl-thiosemicarbazides and thiazolyl-azoles emphasized the importance of optimum hydrophilic-lipophilic balance. These studies showed that the highest bioactivity was observed for the compounds that had medium values for the lipophilicity parameters [42]. 
$\log P$ values that are too high may result in poorer drug solubility. For instance, the widely used fungistatic ketoconazole with a $\log P$ value of 3.73 reportedly belongs to class II of the Biopharmaceutics Classification System, suggesting that the compound has high permeability and low solubility $[43,44]$. Conversely, another antimycotic fluconazole has a $\log P$ value of 0.5 [45]. In theory, such low lipophilicity should be connected with lower membrane permeability [46].

Considering the bioactive potential of phthalides, including 3-n-butylidenephthalide (1) and 3- $n$-butylphthalide (4) $[7-11,47,48]$, we determined the antimicrobial potential of these compounds. Moreover, we also tested whether their derivatives (3-butyl-3hydroxyphthalide (2) and 3-butyl-3-methoxyphthalide (3)) show similar inhibitory properties against selected strains of $C$. albicans. We were particularly interested in whether metabolite (2), with the hydroxyl group in the C-3 position, and its methoxy analogue (3) would also inhibit microorganism growth and whether their lipophilicity influences their activity.

Phthalides from Apiaceae plants, such as 3-n-butyl-4,5-dihydrophthalide and sedanolide, have been previously tested against Candida yeasts. These phthalides were mostly found to be capable of completely inhibiting these yeasts at a concentration of $100 \mu \mathrm{g} / \mathrm{mL}[47,48]$. 3-nButylphthalide (4) showed fungistatic properties against clinical isolates of Candida albicans with an $\mathrm{MIC}_{80}$ of $128 \mu \mathrm{g} / \mathrm{mL}$ [13]. However, 3- $n$-butylidenephthalide (1) has not been previously studied against this microorganism.

Overall, we observed that phthalides (1) and (4) were active against all tested Candida strains and had $\mathrm{MIC}_{50}$ values ranging from below the smallest tested concentration $(23 \mu \mathrm{g} / \mathrm{mL})$ to $123 \mu \mathrm{g} / \mathrm{mL}$ (Table 3). In two cases, the activity of unsaturated lactone (1) was higher than that of its analog, which did not have the double bond in its side chain (4).

Table 3. Minimal inhibitory concentration $\left(\mathrm{MIC}_{50}\right)[\mu \mathrm{g} / \mathrm{mL}]$ for substrate $(\mathbf{1})$, the product of its conversion: 3-butyl-3-hydroxyphthalide (2), its derivatives 3-butyl-3-methoxyphthalide (3) and 3- $n$-butylphthalide (4) when compared with that of fluconazole.

\begin{tabular}{ccccc}
\hline Compound & $\begin{array}{c}\text { C. albicans } \\
\mathbf{6 3 6 / 2 0}\end{array}$ & $\begin{array}{c}\text { C. albicans } \\
\mathbf{5 9 5 / 2 0}\end{array}$ & $\begin{array}{c}\text { C. albicans } \\
\mathbf{3 8}\end{array}$ & $\begin{array}{c}\text { C. albicans } \\
\text { ATTC } \mathbf{9 0 0 2 8}\end{array}$ \\
\hline $\mathbf{1}$ & 88 & $<50$ & $<50$ & 110 \\
$\mathbf{2}$ & 203 & $>250^{1}$ & 250 & $>250^{1}$ \\
$\mathbf{3}$ & 244 & 115 & $>250^{1}$ & $>250^{1}$ \\
$\mathbf{4}$ & 123 & $<50$ & 87 & 89 \\
Fluconazole & $>250^{1}$ & 0.89 & 0.44 & 4.50 \\
\hline
\end{tabular}

${ }^{1}$ Compounds inactive at the highest tested concentration $(250 \mu \mathrm{g} / \mathrm{mL})$.

3-n-Butylidenephthalide (1) efficiently inhibited the growth of the C. albicans clinical isolates 595/20 and 38, with an $\mathrm{MIC}_{50}$ below $50 \mu \mathrm{g} / \mathrm{mL}$. It also inhibited strain 636/20, showing an $\mathrm{MIC}_{50}$ value of $88 \mu \mathrm{g} / \mathrm{mL}$. By contrast, strain 636/20 was not inhibited by the fluconazole at the highest concentration used $(250 \mu \mathrm{g} / \mathrm{mL})$. This phthalide was slightly less active against $C$. albicans ATTC 90028 and had an $\mathrm{MIC}_{50}$ of $110 \mu \mathrm{g} / \mathrm{mL}$. 3- $n$-Butylphthalide (4) was also significantly active against the clinical isolate C. albicans 595/20, showing an $\mathrm{MIC}_{50}$ below $50 \mu \mathrm{g} / \mathrm{mL}$. These inhibitory activities of phthalides (1) and (4) might correlate with their high lipophilicity, and thereby with their sufficient membrane permeability.

It appeared that (-)-3-butyl-3-hydroxyphthalide (2) was slightly active only in the case of strains 636/20 and 38, with $\mathrm{MIC}_{50}$ values of 203 and $250 \mu \mathrm{g} / \mathrm{mL}$, respectively. The compound did not influence the growth of other strains. The lack of activity of 3butyl-3-hydroxyphthalide (2) suggests that 3-n-butylidenephthalide (1) is subjected to an inactivation pathway during its conversion. The lack of activity of (2) corresponds with significantly lower $\log k_{w}$ values, which may indicate that the permeability of the compound is too low. Introduction of the methoxy group in the C-3 position resulted in enhanced activity toward strain 595/20 $\left(\mathrm{MIC}_{50}=115 \mu \mathrm{g} / \mathrm{mL}\right)$ compared with that of the metabolite, but it did not improve its fungistatic activity toward strain $636 / 20$ 
$\left(\mathrm{MIC}_{50}=244 \mu \mathrm{g} / \mathrm{mL}\right)$. However, the lipophilicity of (2) had a value close to that displayed by $3-n$-butylidenephthalide (1). These results suggest that lipophilicity is not the main determinant of the antifungal activity of phthalides. In the case of 3-butyl-3-methoxyphthalide (3), its molecular structure and the occurrence of spatial hindrance may also influence its decreased activity.

Structure-activity dependences for phthalides have been previously proposed. Considering the dependence between the structure and fungistatic activity, available data focuses on preliminary structure-activity tests of more complex 3-substituted phthalides against selected phytopathogens. It has been stated that $-\mathrm{OH}$ and $-\mathrm{NH}_{2}$ groups incorporated in the benzene ring may increase the antifungal activity of phthalides due to the formation of a hydrogen bond with the active site of the pathogen enzyme [49]. In fact, the lack of the activity of the tested compounds (2) and (3) may be explained by the $-\mathrm{OH}$ and $-\mathrm{OCH}_{3}$ groups at the $\mathrm{C}-3$ position. Xiao et al. showed the linkage between the structure of marine fungal phthalide derivatives and peroxisome proliferator-activated receptor gamma (PPAR- $\gamma$ ) binding and activation properties. This study also showed that the occurrence of an -OH group in the benzene ring has a positive effect on higher bioactivity; conversely, the presence of a double side chain at C-3 in phthalides resulted in lower binding and activation properties compared to compounds with a single chain [50].

\section{Materials and Methods}

\subsection{Compounds}

The substrate for the biotransformations-3-n-butylidenephthalide (1) was purchased from Sigma-Aldrich (St. Louis, MO, USA) as the mixture of $(E)$ and $(Z)$ isomers, at the ratio of 9:1 according to the ${ }^{1} \mathrm{H}$ NMR and HPLC (wavelength $274 \mathrm{~nm}$ ).

3-butyl-3-methoxyphthalide (3) was obtained through $24 \mathrm{~h}$ alkaline hydrolysis of a mixture of products $(80 \mathrm{mg})$ obtained in the biotransformation catalyzed by $A$. candidus AM 386. The biotransformation was conducted using $3 \mathrm{~mL} 0.5 \mathrm{M} \mathrm{KOH}$ in $\mathrm{MeOH}$, and esterification was carried out using $4 \mathrm{~mL} 20 \% \mathrm{BF}_{3}$ in methanol. After $1 \mathrm{~h}$, the mixture was briefly filtered using silica gel to remove $\mathrm{BF}_{3}$. The mixture was then eluted by diethyl ether. Crude product was concentrated in a rotary evaporator and purified using silica gel and a hexane:ethyl acetate 19:1 $(v / v)$ eluent. The yield of 3-butyl-3-methoxyphthalide (3) was $41.52 \mathrm{mg}(51.9 \%)$.

3-n-Butylphthalide (4) was synthesized as follows: $n$-butyllithium in hexane (n-BuLi; Sigma-Aldrich, St. Louis, MO, USA) was added dropwise to the phthalic anhydride dissolved in tetrahydrofuran $(7.4 \mathrm{~g}, 0.05 \mathrm{~mol})$ at $-78{ }^{\circ} \mathrm{C}$ (isopropanol $/ \mathrm{CO}_{2}(\mathrm{~s})$ ). The molar ratio of the anhydride to $n$-BuLi was 3:1. The reaction was run for $20 \mathrm{~min}$ and then quenched with $10 \%$ hydrochloric acid, extracted with diethyl ether, washed with water and dried with $\mathrm{MgSO}_{4}$. The solvent was then evaporated. The crude extract was dissolved in $30 \mathrm{~mL}$ THF and $\mathrm{NaBH}_{4}(1.13 \mathrm{~g}$, $0.03 \mathrm{~mol}$; Sigma-Aldrich, St. Louis, MO, USA) was added. The reaction was stopped by adding $10 \%$ hydrochloric acid. THF was evaporated and the mixture was extracted with diethyl ether and washed with water. The organic layer was dried with $\mathrm{MgSO}_{4}$ and collected. After concentration, the crude product was purified by column chromatography using petroleum ether:acetone 3:1 $(v / v)$ as eluent. The yield of 3 - $n$-butylphthalide (4) was $2.12 \mathrm{~g}(67 \%)$. The progress of the reactions was monitored by analytical TLC and GC. The structures of the compounds $(3,4)$ were confirmed by NMR spectroscopy.

\subsection{Microorganisms}

The following strains were used in the biotransformations: Mucor spinosus AM 398, Absidia cylindrospora AM 336, Pycnidiella resinae AM 50, Penicillium chrysogeum AM 112, Chaetomium indicum AM 158, Fusarium culmorum AM 9, Aspergillus candidus AM 386, Laetisporus sulphurens AM 515, Fusicoccum amygdali AM 258 and Ascosphaera apis AM 496. These were all obtained from the Department of Chemistry collection at the Wrocław Uni- 
versity of Environmental and Life Sciences. These strains were maintained on Sabouraud or Czapek agar slants at $4{ }^{\circ} \mathrm{C}$.

Fungistatic activity was detected against Candida albicans ATCC 90028 from American Type Culture Collection, and its clinical isolates Candida albicans 636/20, Candida albicans 595/20 and Candida albicans 38 were obtained from Wrocław Medical University, Poland.

\subsection{Biotransformations}

The biotransformations were conducted in $300 \mathrm{~mL}$ Erlenmeyer flasks. Each strain was inoculated using the sterile Sabouraud medium $(75 \mathrm{~mL})$, which consisted of $30 \mathrm{~g}$ glucose (Chempur, Piekary Ślaskie, Poland), $10 \mathrm{~g}$ bactopeptone (Biocorp, Warszawa, Poland) and $1 \mathrm{~L}$ distilled water ( $\mathrm{pH} 6.88$ ). After 5 days of incubation at $25^{\circ} \mathrm{C}$ on a rotary shaker, $3-n-$ butylidenephthalide (1) was added ( $20 \mathrm{mg}$ dissolved in $0.5 \mathrm{~mL}$ of acetone) and samples were collected every 2 days to measure $\mathrm{pH}$ values. Product yield was determined on days $2,4,6,8$ and 14 . The samples were acidified to $\mathrm{pH} 5$ using hydrochloric acid (if necessary) and extracted using ethyl acetate. The samples were then dried using $\mathrm{MgSO}_{4}$ and subjected to evaporation at $25^{\circ} \mathrm{C}$. Next, the samples were dissolved in methanol, filtered using a $0.45 \mu \mathrm{m}$ PTFE filter and analyzed by HPLC.

Three microorganisms were chosen for the scale-up process: A. cylindrospora AM 336, C. indicum AM 158 and A. candidus AM 386. The preparative biotransformations were conducted in $2000 \mathrm{~mL}$ Erlenmeyer flasks using $500 \mathrm{~mL}$ of a sterile Sabouraud medium and precultivated inoculum, which constituted $10 \%$ of the medium volume. After 5 days of incubation at $25^{\circ} \mathrm{C}$ on a rotary shaker, 3 - $n$-butylidenephthalide (1) was added (150 mg dissolved in $1 \mathrm{~mL}$ acetone) to the culture. The samples were collected every 2 days and the $\mathrm{pH}$ values were measured. The samples were prepared as previously described (except for the evaporation step) and subjected to GC analysis in ethyl acetate. Product mixtures were collected on day 8 of the process for A. candidus AM 386 and on day 14 for C. indicum AM 158 and A. cylindrospora AM 336. The collected samples were acidified with 10\% hydrochloric acid, extracted twice using ethyl acetate and analyzed by RP-TLC.

The product was purified using $250 \mu \mathrm{m}$ thick TLC Silica gel 60 RP-18 F254s plates (Merck, Darmstadt, Germany) with $70 \% \mathrm{MeCN}$ and $30 \% \mathrm{H}_{2} \mathrm{O}$ acidified by $1 \% \mathrm{HCOOH}$ eluent. After separation, the plates were visualized using a UV lamp at 254 and $365 \mathrm{~nm}$. The product was scraped off and extracted with ethyl acetate, after which the organic layer was collected, dried with $\mathrm{MgSO}_{4}$ and evaporated by the rotary evaporator. The structures of the compounds were determined by NMR.

\subsection{Analysis}

TLC analysis was performed on glass plates covered with silica gel 60 F254 (Merck) and developed using hexane:acetone 2:1 $(\mathrm{v} / \mathrm{v})$ eluent. After elucidation, the plates were visualized by a solution of $1 \% \mathrm{Ce}\left(\mathrm{SO}_{4}\right)_{2}$ and $2 \%$ phosphoromolybdic acid in $10 \% \mathrm{H}_{2} \mathrm{SO}_{4}$.

HPLC analysis was performed using a Dionex UltiMate 3000 instrument equipped with a diode array detector (Thermo Fisher Scientfic, Waltham, MA, USA) with a Phenomenex Luna ${ }^{\circledR} 5 \mu \mathrm{m} \mathrm{C18} 100 \AA, 250 \times 4.6 \mathrm{~mm}$ column (Phenomenex, Torrance, CA, USA). The mobile phase was composed of water acidified with $5 \%$ formic acid (A) and methanol (B). Gradient elution conditions were as follows: 0-10 $\mathrm{min}, 35 \% \mathrm{~A} / 65 \% \mathrm{~B} ; 10-20 \mathrm{~min}, 30 \%$ A/70\% B; 21-30 min, $0 \%$ A, 100\% B; 31-35 min, 65\% A/35\% B; and $35-45 \mathrm{~min}, 35 \%$ A, $65 \%$ B. To observe the product, the following parameters were selected: flow rate, $1.0 \mathrm{~mL} / \mathrm{min}$; injection volume, $8 \mu \mathrm{L}$; column incubation temperature, $30^{\circ} \mathrm{C}$; and detection wavelength, $274 \mathrm{~nm}$.

GC analysis (FID, $\mathrm{H}_{2}$ as carrier gas) was performed on an Agilent Technologies $7890 \mathrm{~N}$ GC System (Santa Clara, CA, USA) using a Cyclosil-B column $(30 \mathrm{~m} \times 0.25 \mathrm{~mm} \times 0.25 \mu \mathrm{m}$, Agilent Technologies). The temperature program was $120^{\circ} \mathrm{C}, 200{ }^{\circ} \mathrm{C}\left(8^{\circ} \mathrm{C} / \mathrm{min}\right)$, and $240{ }^{\circ} \mathrm{C}\left(10^{\circ} \mathrm{C} / \mathrm{min}\right)$.

Molecular weights of compounds were assessed using GC-MS on a Saturn 2000 MS Varian Chrompack CP-3800 (Walnut Creek, CA, USA). 
The optical rotation of 3-butyl-3-hydroxyphthalide (2) was measured using JASCO P-2000-Na digital polarimeter (ABL \& E-JASCO, Kraków, Poland) in chloroform. The specific rotations $[\alpha] \begin{gathered}25 \\ 589\end{gathered}$ of product (2) isolated from particular strains were as follows: $-2.4\left(\mathrm{c}=1.0, \mathrm{CHCl}_{3}\right)$ for A. cylindrospora $\mathrm{AM} 336 ;-0.5\left(\mathrm{c}=1.0, \mathrm{CHCl}_{3}\right)$ for A. candidus AM 386; and -3.6 (c = 1.0, $\left.\mathrm{CHCl}_{3}\right)$ for C. indicum AM 158.

NMR spectra $\left({ }^{1} \mathrm{H}\right.$ NMR, ${ }^{13} \mathrm{C}$ NMR) of compounds $(\mathbf{1}),(3,4)$ were recorded on a Bruker Avance DRX-500 spectrometer (Bruker, Billerica, MA, USA) in $\mathrm{CDCl}_{3}$. 3-butyl3-hydroxyphthalide (2) ( ${ }^{1} \mathrm{H}$ NMR, ${ }^{13} \mathrm{C}$ NMR, COSY, HSQC, HMBC) was measured on JNM-ECZS $400 \mathrm{MHz}$ NMR spectrometer (JEOL USA, Peabody, MA, USA). The spectral data are presented below as well as in the attached Supplementary Materials.

3- $n$-butylidenephthalide (1).

${ }^{1} \mathrm{H}$ NMR (500 MHz), $\delta$ (ppm): 0.98 (t, 3H, $\left.J=7.40, \mathrm{H}-11\right), 1.54$ (m, 2H, H-10), 2.45 (q, $\left.2 \mathrm{H}, J_{1}=15.00, J_{2}=7.50, \mathrm{H}-9\right), 5.63(\mathrm{t}, 1 \mathrm{H}, J=7.80, \mathrm{H}-8), 7.49(\mathrm{t}, 1 \mathrm{H}, J=7.30, \mathrm{H}-5), 7.64(\mathrm{~m}$, $2 \mathrm{H}, \mathrm{H}-4), 7.66(\mathrm{~m}, 2 \mathrm{H}, \mathrm{H}-6), 7.88(\mathrm{~d}, 1 \mathrm{H}, J=7.70, \mathrm{H}-7)$.

${ }^{13} \mathrm{C}$ NMR (151 MHz), $\delta$ (ppm): 13.9 (C-11), 22.6 (C-10), 28.0 (C-9), 109.6 (C-8), 119.8 (C-4), 124.6 (C-12), 125.4 (C-7), 129.5 (C-6), 134.3 (C-5), 139.7 (C-3), 145.9 (C-13), 167.3 (C-1). GC-EIMS $189(\mathrm{M}+1)$.

3-butyl-3-hydroxyphthalide (2).

${ }^{1} \mathrm{H}$ NMR: (400 MHz), $\delta$ (ppm): 0.85 (t, 3H, H-11, $\left.J=7.22 \mathrm{~Hz}\right), 1.14(\mathrm{~m}, 1 \mathrm{H}$, one of H-9), $1.31(\mathrm{~m}, 2 \mathrm{H}, \mathrm{H}-10), 1.38(\mathrm{~m}, 1 \mathrm{H}$, one of $\mathrm{H}-9), 2.07\left(\mathrm{ddd}, 1 \mathrm{H}\right.$, one of $\mathrm{H}-8, J_{1}=14.0, J_{2}=11.8$, $\left.J_{3}=4.5 \mathrm{~Hz}\right), 2.20(\mathrm{~m}, 1 \mathrm{H}$, one of H-8) $7.56(\mathrm{~m}, 2 \mathrm{H}, \mathrm{H}-4, \mathrm{H}-6), 7.70(\mathrm{t}, 1 \mathrm{H}, \mathrm{H}-5, J=7.48 \mathrm{~Hz})$, $7.81(\mathrm{~d}, 1 \mathrm{H}, \mathrm{H}-7, \mathrm{~J}=7.52 \mathrm{~Hz})$.

${ }^{13} \mathrm{C}$ NMR (101 MHz), $\delta$ (ppm): 13.9 (C-11), 22.6 (C-10), 25.5 (C-9), 38.7 (C-8), 107.9 (C-3), 122.4 (C-4), 125.6 (C-7), 126.9 (C-12), 130.7 (C-6), 134.8 (C-5), 149.0 (C-13), 168.9 (C-1). 3-butyl-3-hydroxyphthalide (2) due to the low volatility was assessed at the GC-EIMS after esterification as 3-butyl-3-methoxyphthalide (3)-GC-EIMS $221(\mathrm{M}+1)$.

3-butyl-3-methoxyphthalide (3).

${ }^{1} \mathrm{H}$ NMR: (500 MHz), $\delta(\mathrm{ppm}): 0.83(\mathrm{t}, 3 \mathrm{H}, \mathrm{H}-11, J=7.3), 1.12(\mathrm{~m}, 1 \mathrm{H}$, one of $\mathrm{H}-10)$, $1.28(\mathrm{~m}, 2 \mathrm{H}, \mathrm{H}-9), 1.39(\mathrm{~m}, 1 \mathrm{H}$, one of $\mathrm{H}-10), 2.01\left(\mathrm{ddd}, 1 \mathrm{H}\right.$, one of $\mathrm{H}-8, J_{1}=4.58, J_{2}=11.74$, $\left.J_{3}=14.05\right), 2.16\left(\mathrm{ddd}, 1 \mathrm{H}\right.$, one of $\left.\mathrm{H}-8, J_{1}=4.72, J_{2}=11.85, J_{3}=14.04\right) 3.04(\mathrm{~s}, 3 \mathrm{H}, \mathrm{H}-3 \mathrm{a})$, $7.47(\mathrm{~d}, 1 \mathrm{H}, \mathrm{H}-4, J=7.6), 7.59\left(\mathrm{td}, 1 \mathrm{H}, \mathrm{H}-6, J_{1}=0.82, J_{2}=7.55, J_{3}=7.53\right), 7.71(\mathrm{td}, 1 \mathrm{H}, \mathrm{H}-5$, $\left.J_{1}=0.99, J_{2}=7.50, J_{3}=7.50\right), 7.88(\mathrm{~d}, 1 \mathrm{H}, \mathrm{H}-7, J=7.65)$.

${ }^{13} \mathrm{C}$ NMR (151 MHz), $\delta$ (ppm): 13.9 (C-11), 22.7 (C-10), 25.3 (C-9), 38.3 (C-8), 51.2 (C-3a), 111.1 (C-3), 122.6 (C-4), 125.6 (C-7), 128.2 (C-12), 130.7 (C-6), 134.6 (C-5), 146.8 (C-13), $168.5(\mathrm{C}-1)$.

GC-EIMS $221(\mathrm{M}+1)$.

3-n-butylphthalide (4).

${ }^{1} \mathrm{H}$ NMR (500 MHz), $\delta$ (ppm): 0.91 (t, 3H, $\left.J=7.2, \mathrm{H}-11\right), 1.39$ (m, 2H, H-10), 1.48 (m, $2 \mathrm{H}, \mathrm{H}-9), 1.76(\mathrm{~m}, 1 \mathrm{H}$, one of $\mathrm{H}-8), 2.04(\mathrm{~m}, 1 \mathrm{H}$, one of $\mathrm{H}-8), 5.47\left(\mathrm{dd}, 1 \mathrm{H}, J_{1}=7.9, J_{2}=3.7\right.$, $\mathrm{H}-3), 7.44(\mathrm{~d}, 1 \mathrm{H}, J=7.7, \mathrm{CH}-4), 7.52(\mathrm{t}, 1 \mathrm{H}, J=7.5, \mathrm{H}-6), 7.66(\mathrm{t}, 1 \mathrm{H}, J=7.5, \mathrm{H}-5), 7.89(\mathrm{~d}$, $1 \mathrm{H}, J=7.7, \mathrm{H}-7)$.

${ }^{13} \mathrm{C}$ NMR (151 MHz), $\delta$ (ppm): 14.0 (C-11), 22.6 (C-10), 27.0 (C-9), 34.6 (C-8), 81.6 (C-3), 121.8 (C-4), 125.8 (C-7), 126.3 (C-12) 129.1 (C-6), 134.1 (C-5), 150.3 (C-13), 170.8 (C-1).

GC-EIMS $191(\mathrm{M}+1)$.

\subsection{Lipophilicity}

The concentration of tested compounds (1-4) was $0.1 \mathrm{mg} / \mathrm{mL}$. Dead time $\left(\mathrm{t}_{0}\right)$ was measured by injecting $1 \%$ aqueous $\mathrm{NaNO}_{3}$ solution. The injection volume was $10 \mu \mathrm{L}$, the temperature was $35^{\circ} \mathrm{C}$ and the flow rate was $1.5 \mathrm{~mL} / \mathrm{min}$. The retention time $\left(t_{R}\right)$ of the samples was also assessed by RP-HPLC in triplicate using the abovementioned column and isocratic elution. The eluents consisted of methanol and water, both of which were acidified by $1 \%$ formic acid $v / v$ at $60-80 \%$ of the organic phase. The retention factor $(k)$ was calculated according to the following equation: $k=\left(t_{R}-t_{0}\right) / t_{0}$. A graph 
of $\log \mathrm{k}$ as a function of the volume fraction of organic solvent was plotted. The value of the chromatographic lipophilicity index, $\log \mathrm{k}_{\mathrm{w}}(\log \mathrm{k}$ value with $0 \%$ methanol in the mobile phase), was determined by extrapolating this correlation. The chromatographic hydrophobicity index $\varphi_{0}$ was also assessed as the volume fraction of methanol that yields a $\log \mathrm{k}$ value of 0 [31]. Theoretical $\log P$ (partition coefficient) values were calculated with the use of ALOGPS 2.1. Pearson's correlation coefficients between the $\log P$ and $\log \mathrm{k}_{\mathrm{w}}$ were determined using GraphPad Prism, and differences with $p<0.05$ were considered statistically significant.

\subsection{Fungistatic Activity}

Compounds (1-4) were tested against four Candida albicans strains (C. albicans ATTC 90028 and its clinical isolates C. albicans 636/20, C. albicans 595/20 and C. albicans 38) using the broth microdilution technique. The medium used for the tests was YPD, consisting of $20 \mathrm{~g}$ glucose (Chempur, Piekary Ślaskie, Poland), $20 \mathrm{~g}$ bactopeptone (Biocorp, Warszawa, Poland), $10 \mathrm{~g}$ yeast extract (BTL, Łódź, Poland) and $1 \mathrm{~L}$ distilled water; the $\mathrm{pH}$ was adjusted to 6.5. The solutions of the compounds were prepared in dimethyl sulfoxide (DMSO) and diluted in YPD to obtain final concentrations in the range of 50-250 $\mu \mathrm{g} / \mathrm{mL}$. Fluconazole was tested at the range of $0.064-64 \mu \mathrm{g} / \mathrm{mL}$ with the exception of the resistant strain $636 / 20$, which was additionally tested in the range of 50-250 $\mu \mathrm{g} / \mathrm{mL}$. Next, $100 \mu \mathrm{L}$ of each solution was pipetted into wells of a 96-well microtiter plate. The inoculum was standardized to $0.5 \mathrm{McFarland}$ standard and then diluted to obtain the final suspension with a cell density of $0.5 \times 10^{3}$ to $2.5 \times 10^{3} \mathrm{CFU} / \mathrm{mL}$. The inoculum size used was $100 \mu \mathrm{L}$. The positive control comprised DMSO added in the same concentration as the tested compounds in the inoculum, while the negative control was DMSO diluted in the broth without the addition of inoculum. All samples were tested at least in triplicate. The microtiter plates were incubated at $35{ }^{\circ} \mathrm{C}$ for $24 \mathrm{~h}$ in a Biosan PST-60 HL ThermoShaker (Riga, Latvia) at $1000 \mathrm{rpm}$. The fungistatic activity of the compounds was assessed by measuring the absorbance at a wavelength of $595 \mathrm{~nm}$ (Epoch, BioTek, Winooski, VT, USA) to determine the $\mathrm{MIC}_{50}$ value (i.e., the concentration of a compound required to inhibit the growth of $50 \%$ of microorganisms).

\section{Conclusions}

In this study, we confirmed the utility of microbially catalyzed biotransformation for obtaining the mammalian metabolite (2) of bioactive 3- $n$-butylidenephthalide (1). We show that microbiological transformations can efficiently produce the target compound and can be used to better understand phthalide lactone metabolism. Overall, 10 fungal strains were tested, five of which efficiently produced hydroxy-3-butylphthalide (2). We proposed three mechanisms by which 3- $n$-butylidenephthalide (1) conversion may occur. Even though hydroxylation remains popular in xenobiotic metabolism, we excluded this pathway based on ${ }^{13} \mathrm{C}$ NMR spectra and suggested the hydration pathway as the most probable mechanism. Valuable contributions of this research include the analysis of the lipophilicity and fungistatic activity of both phthalides (1) and (4) and the metabolite (2). Antifungal assays revealed the potential of both 3- $n$-butylidenephthalide (1) and 3- $n$-butylphthalide (4) against clinical isolates of $C$. albicans, with an $\mathrm{MIC}_{50}$ value below $50 \mu \mathrm{g} / \mathrm{mL}$. We did not observe the influence of a double bond-containing side chain on the activity of compounds (1) and (4). We noticed weak or even a lack of inhibitory properties for metabolite (2), which has lower lipophilicity and presumably lower permeability than compounds (1) and (4). We did not observe a straightforward correlation between lipophilicity and fungistatic activity. Apart from the lipophilicity, the spatial structure of compounds is the factor that influences their biological activity. The presence of $-\mathrm{OH}$ groups in compound (2) or $-\mathrm{OCH}_{3}$ groups in compound (3) causes the decrease of antifungal activity compared to that of 3-n-butylphthalide (4). Compound (1), which has a double bond in its structure, shows similar polarity to 3-butyl-3-methoxyphthalide (3); however, this compound had high 
biological activity. Considering the possible applications for phthalides, there is a necessity for further research, particularly regarding the biological activity of their metabolites.

Supplementary Materials: The following are available online at https:/ /www.mdpi.com/article/10 $.3390 /$ ijms22147600/s1.

Author Contributions: Conceptualization, J.G. and T.O.; methodology, J.G., T.O., F.B.; formal analysis, J.G., T.O.; investigation, J.G., P.K.; resources, J.G., T.O., F.B.; writing-original draft preparation, J.G., T.O.; writing-review and editing, F.B., P.K.; visualization, J.G.; supervision, T.O.; funding acquisition, J.G. All authors have read and agreed to the published version of the manuscript.

Funding: This research and APC was funded by the project "UPWR 2.0: international and interdisciplinary program of development of Wrocław University of Environmental and Life Sciences", co-financed by the European Social Fund under the Operational Program Knowledge Education Development, under contract No. POWR.03.05.00-00-Z062/18 of 4 June 2019.

Institutional Review Board Statement: Not applicable.

Informed Consent Statement: Not applicable.

Data Availability Statement: The data presented in this study are available on request from the corresponding author.

Conflicts of Interest: The authors declare no conflict of interest.

\section{References}

1. Chen, H.-C.; Tsai, Y.-J.; Lin, L.-Y.; Wu, C.-S.; Tai, S.-P.; Chen, Y.-C.; Chiang, H.-M. Volatile Compounds from Roots, Stems and Leaves of Angelica Acutiloba Growing in Taiwan. Nat. Prod. Commun. 2014, 9, 583-586. [CrossRef]

2. Chen, W.-R.; Yu, Y.; Zulfajri, M.; Lin, P.-C.; Wang, C.C. Phthalide Derivatives from Angelica Sinensis Decrease Hemoglobin Oxygen Affinity: A New Allosteric-Modulating Mechanism and Potential Use as 2,3-BPG Functional Substitutes. Sci. Rep. 2017, 7, 5504. [CrossRef]

3. Baananou, S.; Piras, A.; Marongiu, B.; Dessì, M.A.; Falconieri, D.; Porcedda, S.; Rosa, A.; Boughattas, N.A. Antiulcerogenic Activity of Apium Graveolens Seeds Oils Isolated by Supercritical CO2. Afr. J. Pharm. Pharmacol. 2012, 6, 752-762. [CrossRef]

4. Chae, S.-H.; Kim, S.-I.; Yeon, S.-H.; Lee, S.-W.; Ahn, Y.-J. Adulticidal Activity of Phthalides Identified in Cnidium Officinale Rhizome to B- and Q-Biotypes of Bemisia Tabaci. J. Agric. Food Chem. 2011, 59, 8193-8198. [CrossRef] [PubMed]

5. Spréa, R.M.; Fernandes, Â.; Finimundy, T.C.; Pereira, C.; Alves, M.J.; Calhelha, R.C.; Canan, C.; Barros, L.; Amaral, J.S.; Ferreira, I.C.F.R. Lovage (Levisticum Officinale W.D.J. Koch) Roots: A Source of Bioactive Compounds towards a Circular Economy. Resources 2020, 9, 81. [CrossRef]

6. León, A.; Toscano, R.A.; Tortoriello, J.; Delgado, G. Phthalides and Other Constituents from Ligusticum Porteri; Sedative and Spasmolytic Activities of Some Natural Products and Derivatives. Nat. Prod. Res. 2011, 25, 1234-1242. [CrossRef]

7. Jia, J.; Wei, C.; Liang, J.; Zhou, A.; Zuo, X.; Song, H.; Wu, L.; Chen, X.; Chen, S.; Zhang, J.; et al. The Effects of DL-3-n-Butylphthalide in Patients with Vascular Cognitive Impairment without Dementia Caused by Subcortical Ischemic Small Vessel Disease: A Multicentre, Randomized, Double-Blind, Placebo-Controlled Trial. Alzheimer's Dement. 2016, 12, 89-99. [CrossRef] [PubMed]

8. Yeh, J.-C.; Cindrova-Davies, T.; Belleri, M.; Morbidelli, L.; Miller, N.; Cho, C.-W.C.; Chan, K.; Wang, Y.-T.; Luo, G.-A.; Ziche, M.; et al. The Natural Compound N-Butylidenephthalide Derived from the Volatile Oil of Radix Angelica Sinensis Inhibits Angiogenesis In Vitro and In Vivo. Angiogenesis 2011, 14, 187-197. [CrossRef] [PubMed]

9. Zhou, Q.-M.; Zhang, J.-J.; Li, S.; Chen, S.; Le, W.-D. N-Butylidenephthalide Treatment Prolongs Life Span and Attenuates Motor Neuron Loss in SOD1 G93A Mouse Model of Amyotrophic Lateral Sclerosis. CNS Neurosci. Ther. 2017, 23, 375-385. [CrossRef] [PubMed]

10. Nam, K.N.; Kim, K.-P.; Cho, K.-H.; Jung, W.-S.; Park, J.-M.; Cho, S.-Y.; Park, S.-K.; Park, T.-H.; Kim, Y.-S.; Lee, E.H. Prevention of Inflammation-Mediated Neurotoxicity by Butylidenephthalide and Its Role in Microglial Activation: BP Inhibits Microglial Inflammatory Response. Cell Biochem. Funct. 2013, 31, 707-712. [CrossRef]

11. Brindis, F.; Rodríguez, R.; Bye, R.; González-Andrade, M.; Mata, R. (Z)-3-Butylidenephthalide from Ligusticum porteri, an $\alpha$-Glucosidase Inhibitor. J. Nat. Prod. 2011, 74, 314-320. [CrossRef]

12. Sim, Y.; Shin, S. Combinatorial Anti-Trichophyton Effects of Ligusticum Chuanxiong Essential Oil Components with Antibiotics. Arch. Pharm. Res. 2008, 31, 497-502. [CrossRef] [PubMed]

13. Gong, Y.; Liu, W.; Huang, X.; Hao, L.; Li, Y.; Sun, S. Antifungal Activity and Potential Mechanism of N-Butylphthalide Alone and in Combination With Fluconazole Against Candida Albicans. Front. Microbiol. 2019, 10, 1461. [CrossRef] [PubMed]

14. Aguiar, F.L.L.D.; Santos, N.C.; de Paula Cavalcante, C.S.; Andreu, D.; Baptista, G.R.; Gonçalves, S. Antibiofilm Activity on Candida Albicans and Mechanism of Action on Biomembrane Models of the Antimicrobial Peptide Ctn [15-34]. Int. J. Mol. Sci. 2020, 21, 8339. [CrossRef] [PubMed] 
15. Bhattacharya, S.; Sae-Tia, S.; Fries, B.C. Candidiasis and Mechanisms of Antifungal Resistance. Antibiotics 2020, 9, 312. [CrossRef] [PubMed]

16. Singh, A.; Verma, R.; Murari, A.; Agrawal, A. Oral Candidiasis: An Overview. J. Oral Maxillofac. Pathol. 2014, 18, 81. [CrossRef]

17. Spettel, K.; Barousch, W.; Makristathis, A.; Zeller, I.; Nehr, M.; Selitsch, B.; Lackner, M.; Rath, P.-M.; Steinmann, J.; Willinger, B. Analysis of Antifungal Resistance Genes in Candida Albicans and Candida Glabrata Using next Generation Sequencing. PLoS ONE 2019, 14, e0210397. [CrossRef]

18. Yassin, M.T.; Mostafa, A.A.; Al-Askar, A.A.; Bdeer, R. In Vitro Antifungal Resistance Profile of Candida Strains Isolated from Saudi Women Suffering from Vulvovaginitis. Eur. J. Med. Res. 2020, 25, 1. [CrossRef] [PubMed]

19. Bühler, T.; Medinger, M.; Bouitbir, J.; Krähenbühl, S.; Leuppi-Taegtmeyer, A. Hepatotoxicity Due to Azole Antimycotic Agents in a HLA B * 35:02-Positive Patient. Front. Pharmacol. 2019, 10, 645. [CrossRef]

20. Van Daele, R.; Spriet, I.; Wauters, J.; Maertens, J.; Mercier, T.; Van Hecke, S.; Brüggemann, R. Antifungal Drugs: What Brings the Future? Med Mycol. 2019, 57, S328-S343. [CrossRef]

21. Kebamo, S.; Tesema, S. The Role of Biotransformation in Drug Discovery and Development. J. Drug Metab. Toxicol. 2015, 6. [CrossRef]

22. Duan, F.; Xu, W.; Liu, J.; Jia, Z.; Chen, K.; Chen, Y.; Wang, M.; Ma, K.; Dong, J.; Chen, L.; et al. Preparing the Key Metabolite of Z -Ligustilide in Vivo by a Specific Electrochemical Reaction. J. Sep. Sci. 2018, 41, 2799-2807. [CrossRef] [PubMed]

23. Shanu-Wilson, J.; Evans, L.; Wrigley, S.; Steele, J.; Atherton, J.; Boer, J. Biotransformation: Impact and Application of Metabolism in Drug Discovery. ACS Med. Chem. Lett. 2020, 11, 2087-2107. [CrossRef] [PubMed]

24. Kelly, S.L.; Kelly, D.E. Microbial Cytochromes P450: Biodiversity and Biotechnology. Where Do Cytochromes P450 Come from, What Do They Do and What Can They Do for Us? Philos. Trans. R. Soc. B: Biol. Sci. 2013, 368, 20120476. [CrossRef] [PubMed]

25. Lu, W.; Feng, J.; Chen, X.; Bao, Y.-J.; Wang, Y.; Wu, Q.; Ma, Y.; Zhu, D. Distinct Regioselectivity of Fungal P450 Enzymes for Steroidal Hydroxylation. Appl. Environ. Microbiol. 2019, 85, e01182-19. [CrossRef] [PubMed]

26. Hüttel, W.; Hoffmeister, D. Fungal Biotransformations in Pharmaceutical Sciences. In Industrial Applications; Hofrichter, M., Ed.; Springer: Berlin/Heidelberg, Germany, 2011; pp. 293-317.

27. Diao, X.; Deng, P.; Xie, C.; Li, X.; Zhong, D.; Zhang, Y.; Chen, X. Metabolism and Pharmacokinetics of 3- $n$-Butylphthalide (NBP) in Humans: The Role of Cytochrome P450s and Alcohol Dehydrogenase in Biotransformation. Drug Metab. Dispos. 2013, 41, 430-444. [CrossRef]

28. Yan, R.; Ko, N.L.; Ma, B.; Tam, Y.K.; Lin, G. Metabolic Conversion from Co-Existing Ingredient Leading to Significant Systemic Exposure of Z-Butylidenephthalide, a Minor Ingredient in Chuanxiong Rhizoma in Rats. Curr. Drug Metab. 2012, 13, 524-534. [CrossRef]

29. Nycz-Empel, A.; Bober, K.; Wyszomirski, M.; Kisiel, E.; Zięba, A. The Application of CA and PCA to the Evaluation of Lipophilicity and Physicochemical Properties of Tetracyclic Diazaphenothiazine Derivatives. J. Anal. Methods Chem. 2019, $2019,8131235$. [CrossRef]

30. Ciura, K.; Fedorowicz, J.; Andrić, F.; Greber, K.E.; Gurgielewicz, A.; Sawicki, W.; Sączewski, J. Lipophilicity Determination of Quaternary (Fluoro)Quinolones by Chromatographic and Theoretical Approaches. Int. J. Mol. Sci. 2019, 20, 5288. [CrossRef]

31. Klose, M.; Theiner, S.; Varbanov, H.; Hoefer, D.; Pichler, V.; Galanski, M.; Meier-Menches, S.; Keppler, B. Development and Validation of Liquid Chromatography-Based Methods to Assess the Lipophilicity of Cytotoxic Platinum (IV) Complexes. Inorganics 2018, 6, 130. [CrossRef]

32. Chmiel, T.; Mieszkowska, A.; Kempińska-Kupczyk, D.; Kot-Wasik, A.; Namieśnik, J.; Mazerska, Z. The Impact of Lipophilicity on Environmental Processes, Drug Delivery and Bioavailability of Food Components. Microchem. J. 2019, 146, 393-406. [CrossRef]

33. Lipinski, C.A. Lead- and Drug-like Compounds: The Rule-of-Five Revolution. Drug Discov. Today Technol. 2004, 1, 337-341. [CrossRef]

34. Fernandes, T.R.; Segorbe, D.; Prusky, D.; Di Pietro, A. How Alkalinization Drives Fungal Pathogenicity. PLoS Pathog. 2017, 13, e1006621. [CrossRef]

35. Zöllner, A.; Buchheit, D.; Meyer, M.R.; Maurer, H.H.; Peters, F.T.; Bureik, M. Production of Human Phase 1 and 2 Metabolites by Whole-Cell Biotransformation with Recombinant Microbes. Bioanalysis 2010, 2, 1277-1290. [CrossRef] [PubMed]

36. Lin, C.-I.; McCarty, R.M.; Liu, H. The Enzymology of Organic Transformations: A Survey of Name Reactions in Biological Systems. Angew. Chem. Int. Ed. 2017, 56, 3446-3489. [CrossRef] [PubMed]

37. Yan, R.; Ko, N.L.; Li, S.-L.; Tam, Y.K.; Lin, G. Pharmacokinetics and Metabolism of Ligustilide, a Major Bioactive Component in Rhizoma Chuanxiong, in the Rat. Drug Metab. Dispos. 2008, 36, 400-408. [CrossRef] [PubMed]

38. Engleder, M.; Pichler, H. On the Current Role of Hydratases in Biocatalysis. Appl. Microbiol. Biotechnol. 2018, 102, 5841-5858. [CrossRef]

39. Li, C.-Y.; Qi, L.-W.; Li, P. Correlative Analysis of Metabolite Profiling of Danggui Buxue Tang in Rat Biological Fluids by Rapid Resolution LC-TOF/MS. J. Pharm. Biomed. Anal. 2011, 55, 146-160. [CrossRef]

40. Zheng, B.; West, L.M. Estimating The Lipophilicity Of Natural Products Using A Polymeric Reversed Phase Hplc Method. J. Liq. Chromatogr. Relat. Technol. 2009, 33, 118-132. [CrossRef]

41. Sima, I.A.; Kot-Wasik, A.; Wasik, A.; Namieśnik, J.; Sârbu, C. Assessment of Lipophilicity Indices Derived from Retention Behavior of Antioxidant Compounds in RP-HPLC. Molecules 2017, 22, 550. [CrossRef] [PubMed] 
42. Tamaian, R.; Moţ, A.; Silaghi-Dumitrescu, R.; Ionuţ, I.; Stana, A.; Oniga, O.; Nastasă, C.; Benedec, D.; Tiperciuc, B. Study of the Relationships between the Structure, Lipophilicity and Biological Activity of Some Thiazolyl-Carbonyl-Thiosemicarbazides and Thiazolyl-Azoles. Molecules 2015, 20, 22188-22201. [CrossRef]

43. Ghazal, H.S.; Dyas, A.M.; Ford, J.L.; Hutcheon, G.A. The Impact of Food Components on the Intrinsic Dissolution Rate of Ketoconazole. Drug Dev. Ind. Pharm. 2015, 41, 1647-1654. [CrossRef] [PubMed]

44. Tsume, Y.; Mudie, D.M.; Langguth, P.; Amidon, G.E.; Amidon, G.L. The Biopharmaceutics Classification System: Subclasses for in Vivo Predictive Dissolution (IPD) Methodology and IVIVC. Eur. J. Pharm. Sci. 2014, 57, 152-163. [CrossRef] [PubMed]

45. Corrêa, J.C.R.; Salgado, H.R.N. Review of Fluconazole Properties and Analytical Methods for Its Determination. Crit. Rev. Anal. Chem. 2011, 41, 124-132. [CrossRef]

46. Bennion, B.J.; Be, N.A.; McNerney, M.W.; Lao, V.; Carlson, E.M.; Valdez, C.A.; Malfatti, M.A.; Enright, H.A.; Nguyen, T.H.; Lightstone, F.C.; et al. Predicting a Drug's Membrane Permeability: A Computational Model Validated With in Vitro Permeability Assay Data. J. Phys. Chem. B 2017, 121, 5228-5237. [CrossRef] [PubMed]

47. Momin, R.A.; Nair, M.G. Mosquitocidal, Nematicidal, and Antifungal Compounds from Apium Graveolens L. Seeds. J. Agric. Food Chem. 2001, 49, 142-145. [CrossRef]

48. Pannek, J.; Gach, J.; Boratyński, F.; Olejniczak, T. Antimicrobial Activity of Extracts and Phthalides Occurring in Apiaceae Plants: Antimicrobial Activity of Phthalides. Phytother. Res. 2018, 32, 1459-1487. [CrossRef]

49. Fan, L.; Luo, B.; Luo, Z.; Zhang, L.; Fan, J.; Xue, W.; Tang, L.; Li, Y. Synthesis and Antifungal Activities of 3-Substituted Phthalide Derivatives. Z. Für Nat. B 2019, 74, 811-818. [CrossRef]

50. Xiao, B.; Yin, J.; Park, M.; Liu, J.; Li, J.L.; Kim, E.L.; Hong, J.; Chung, H.Y.; Jung, J.H. Design and Synthesis of Marine Fungal Phthalide Derivatives as PPAR- $\gamma$ Agonists. Bioorganic Med. Chem. 2012, 20, 4954-4961. [CrossRef] 